\title{
Repair of reinforced concrete beams using carbon fiber reinforced polymer
}

\author{
Abdul Saboor Karzad $^{1, *}$, Salah Al Toubat ${ }^{1}$, Mohammed Maalej ${ }^{1}$, and Pierre Estephane ${ }^{2}$ \\ ${ }^{1}$ Department of Civil \& Environmental Engineering, Sustainable Construction Materials and \\ Structural Systems Research Group, University of Sharjah,P.O.Box 27272, Sharjah, UAE \\ ${ }^{2}$ GCP Applied Technologies, P.O.Box 5006, Dubai, UAE
}

\begin{abstract}
This research paper is part of an ongoing research on the behaviour of Reinforced Concrete (RC) beams retrofitted with Externally Bonded Carbon Fiber Reinforced Polymer (EB-CFRP). A total of 5 largescale rectangular beams, previously damaged due to shear loading, were repaired and strengthened with EB-CFRP and tested in this study. The major cracks of the damaged beams were injected with epoxy and the beams were wrapped with 2 layers of EB-CFRP discrete strips with $100 \mathrm{~mm}$ width and $150 \mathrm{~mm}$ center to center spacing. The beams were instrumented and tested to failure under three points loading in simply supported configuration. The measured test parameters were the beams deflection, maximum load, and the strain in the FRP strips. The failure mode was also observed. The results showed that applying EB-FRP strips increased the shear strength significantly relative to the original shear capacity of the beam. The results demonstrate that the application of EBFRP strips used in this study is an effective repair method that can be used to repair and strengthen damaged beams.
\end{abstract}

\section{Introduction}

Most of the Existing structures such as bridges and buildings are made of reinforced concrete (RC). RC is an economical and versatile construction material and in most cases, it is strong and durable. However, certain circumstances; for instance, poor design and construction, low-quality construction materials, design and construction according to old earthquake resistant design guidelines, environmental effects (e.g. corrosion, freeze-thaw, etc.), and other deteriorating factors can decrease the service life of the structures [1]-[3]. Therefore, repair and retrofitting of these deteriorated structures is essential to maintain and extend their designed service life [4], [5].

The traditional rehabilitation methods (i.e. adding new structural members, enlarging the existing section, bonding steel plates and etc.) are in line with several disadvantage such as difficult and time consuming application, and lack of durability [5]. To overcome these disadvantages, the application of EB-FRP sheets has emerged as an innovative rehabilitation technology in response to the increasing demand for retrofitting of existing structures[6]-[8]. The EB-FRP technology has several advantages over traditional rehabilitation techniques. The advantages are high tensile strength, noncorrosive,

* Corresponding Author akarzad@sharjah.ac.ae 
nonmagnetic, lightweight, quick and easy installation and etc.[1]-[7], [9]-[13]. It is worth nothing that several experimental and analytical researches have been conducted since 1990 s, to investigate the technique and behaviour of this new technology and establish its effectiveness [12]-[18]. Based on these studies some guidelines are developed [21]-[23].

EB-FRP repair and strengthening can be executed in three types of applications: confinement, flexural and shear strengthening[3], [19]-[21].The behaviour of the first two types of applications (i.e. confinement and flexural strengthening) is well understood however the shear strengthening using EB-FRP (i.e. full wrapping, U-jacketing, side bonding and near surface mounted (NSM) in vertical or inclined orientation) is still a matter of further research [12], [18], [22]-[24].

Reinforced concrete structures are designed such that flexural failure is the governed mode of failure and shear failure is prevented. To prevent the sudden failure (shear) and assure the ductile failure (flexural), the RC beams should acquire adequate shear strength[25]. The later requirement is the key impetus for conducting this research which is investigating the repair and strengthening of shear deficient beams using EB-CFRP.

\section{Experimental program}

\subsection{Materials properties}

The EB-CFRP discrete strips used in this study, are unidirectional woven carbon fiber flexible sheet. The CFRP sheet has a thickness $\left(\mathrm{t}_{\mathrm{frp}}\right)$ of $0.167 \mathrm{~mm}$, a tensile modulus of $230 \mathrm{GPa}$, tensile strength of $4.9 \mathrm{GPa}$, and ultimate elongation of $2.1 \%$. The CFRP sheets were encapsulated and bonded to the specimens using a compatible polymeric encapsulation resin through the wet application process of bonding.

Prior to wrapping the pre-damaged beams with EB-FRP, an appropriate epoxy (Denepox ${ }^{\mathrm{TM}-40}$ ) was used to inject the existing major cracks of the beams. Denepox is an ultra-low viscosity, 2-component epoxy resin for structural injections in concrete that after mixing both components cure into a rigid compound.

The concrete mix used for casting the beams had a $28^{\text {th }}$ day compressive strength (fc') of $38.4 \mathrm{MPa}$ according to ASTM C39. The beams longitudinal reinforcement had a yield strength of fy $=550 \mathrm{MPa}$, and the transverse reinforcement yield strength was fy $=290$ $\mathrm{MPa}$.

\subsection{Test specimens and matrix}

A total of 5 full-scale damaged RC beams (DB) in two types: with minimum shear reinforcement and without shear reinforcement, were repaired (RB) and retested. Each type of specimen consisted of pairs of identical slender pre-damaged beams tested in an earlier research work (Ardavan Yazdanbakhsh 2008). The beams are rectangular cross-section $(390 \times 230 \mathrm{~mm})$ with effective depth of $330 \mathrm{~mm}$, length of $2700 \mathrm{~mm}$, span of $2300 \mathrm{~mm}$, and shear span to depth ratio (a/d) equal to 3.5. Photos of typical specimens previously tested by Ardavan are shown in Fig.1 [26].

All tested beams were heavily reinforced in flexure by placing three longitudinal steel bars with a nominal diameter of $32 \mathrm{~mm}$. Heavy flexural reinforcement was used to ensure that the shear failure is the dominant mode of failure. In addition, two longitudinal steel bars with a nominal diameter of $10 \mathrm{~mm}$ were provided in compression zone of the beams. Moreover, 2 out of 5 beams were reinforced in shear with minimum shear reinforcement ratio (according to ACI 318 ) using $6 \mathrm{~mm}$ steel stirrups spaced at $200 \mathrm{~mm}$ with a clear cover of $20 \mathrm{~mm}$. 


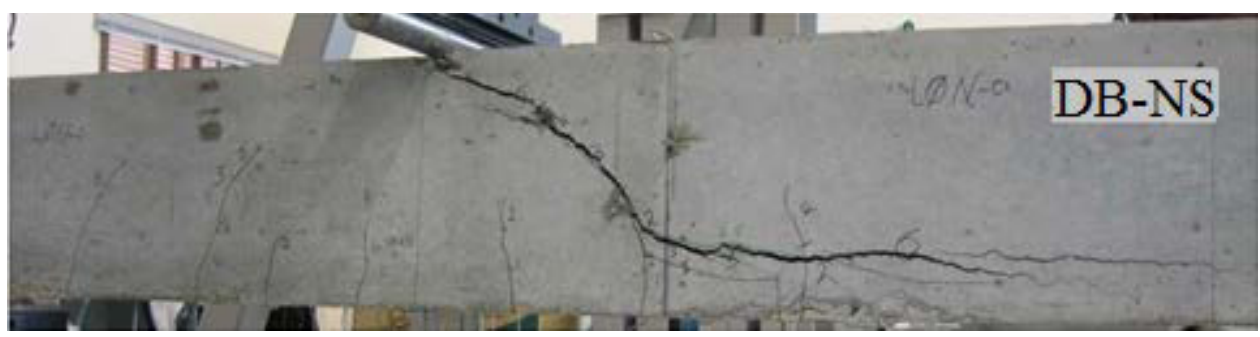

(a)

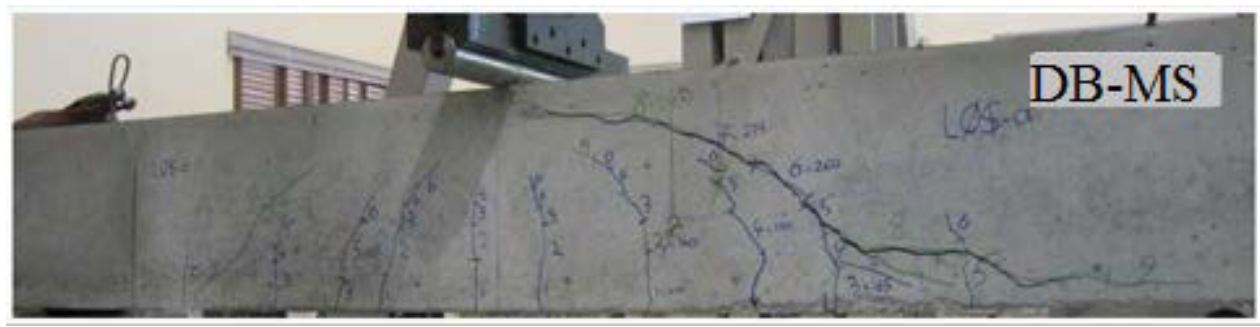

(b)

Fig. 1. Pre-damaged beams (source [26]), a) without stirrups, b) with minimum ratio of stirrups

The test matrix of the experimental program is summarized in Table 1. Each specimen is identified by a label that shows the condition of beams, ratio of conventional shear reinforcement, number of EB-CFRP layers, and ends with a small letter showing identity of duplicate beams. The label of damaged beams starts with two letters DB while the repaired beams starts with RB. For instance, the beam DB-NS-a means damaged beam (DB) without steel stirrups (NS), while DB-MS-a means damaged beam with minimum ratio of steel stirrups (MS) according to ACI-318. Similarly, specimen RB-NS-2L-a means Repaired Beam (RB) without stirrups (NS) and wrapped with 2 layers of EB-FRP (2L), and specimen RB-MS-2L-a means Repaired Beam with minimum ratio of steel stirrups and wrapped with 2 layers of EB-FRP (1L). While RB-NS-0L-c means Repaired beam with epoxy injection only and without stirrups.

Table 1. Test matrix.

\begin{tabular}{|c|c|c|}
\hline Label & Condition & Test Objective \\
\hline RB-NS-2L-a & Repaired / Wrapped & $\begin{array}{c}\text { Extent of shear strength recovery using } \\
\text { EB-FRP retrofitting. }\end{array}$ \\
\hline RB-NS-2L-b & Repaired / Wrapped & $\begin{array}{c}\text { Extent of shear strength recovery using } \\
\text { EB-FRP retrofitting. }\end{array}$ \\
\hline RB-MS-2L-a & Repaired / Wrapped & $\begin{array}{c}\text { Extent of shear strength recovery using } \\
\text { EB-FRP retrofitting. }\end{array}$ \\
\hline RB-MS-2L-b & Repaired / Wrapped & $\begin{array}{c}\text { Extent of shear strength recovery using } \\
\text { EB-FRP retrofitting. }\end{array}$ \\
\hline RB-NS-0L-c & Repaired / Unwrapped & $\begin{array}{c}\text { Injected epoxy contribution to shear strength } \\
\text { recovery. }\end{array}$ \\
\hline
\end{tabular}




\subsection{Repair methodology}

Repair process of the beams shown in Fig.2, included steps which are: cleaning the major crack with air blower, sealing the cracks and attaching the packers with an appropriate mortar (Nitomortar $\mathrm{FC}^{\mathrm{TM}}$ ), injecting and filling the major cracks using epoxy (Denepox ${ }^{\mathrm{TM}}$ ), surface grinding with diamond grinder, and surface preparation with Nitomortar ${ }^{\mathrm{TM}}$ and primer-coat (Nitowrap ${ }^{\mathrm{TM}}$ ), and finally hand lay-up application of U-shaped CFRP discrete strips (Nitowrap FRC $300^{\mathrm{TM}}$ ). It should be mentioned that before bonding CFRP strips to the specimens, the corners of the beams were chamfered to prevent stress concentration in the sharp bottom edges of the beams.

Four out of five beams were wrapped with 2 layers (2L) of EB-CFRP in U-jacketing scheme and one beam was repaired with epoxy injection only $(0 \mathrm{~L})$. It is worth nothing that prior to bonding the CFRP strips, the pre-existing major cracks in the beams were injected with epoxy. The epoxy was injected using the specific pressure pump through the attached vessels (packers) on the surface of the specimens. The EB-CFRP strips bonded to the beams, had a width (wfrp) of $100 \mathrm{~mm}$ and a center to center spacing (sfrp) of $150 \mathrm{~mm}$ and a net spacing of $50 \mathrm{~mm}$ as shown in Fig. 3.

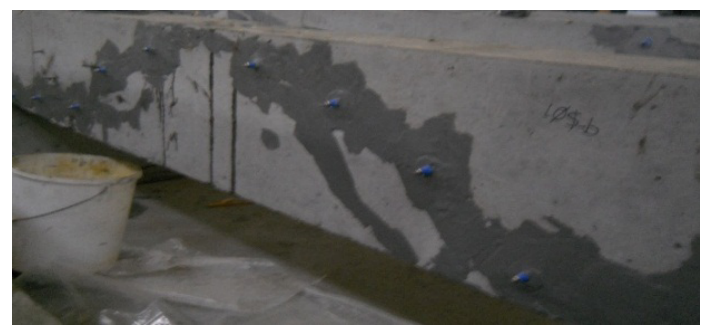

(a)

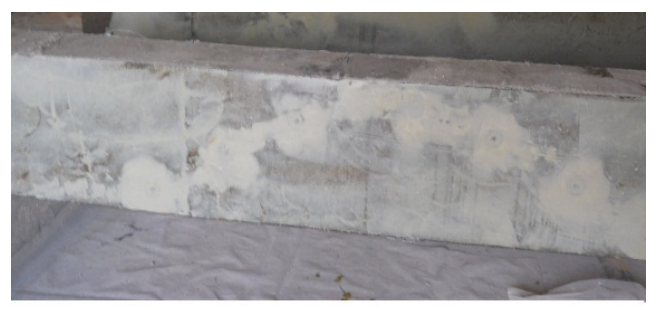

(c)

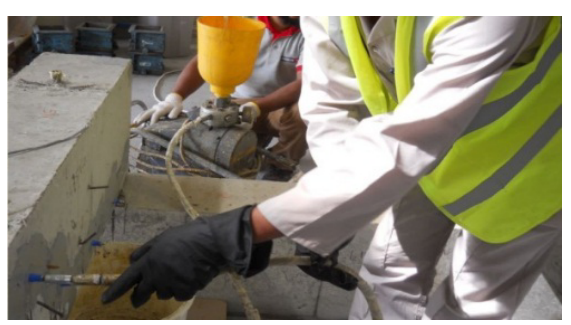

(b)

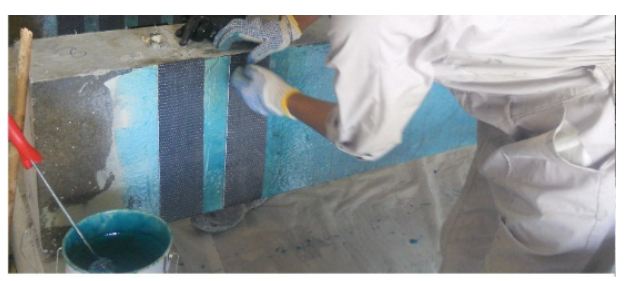

(d)

Fig. 2. . a) Pre-damaged beam with attached packers on the main crack, b) Injecting epoxy using pressure pump, c) Beam ready for wrapping after surface grinding and primer coat application, d) Wrapping the beam with CFRP strips using compatible encapsulation resin.

\subsection{Test setup and instrumentation}

The test setup consisted of a simply supported loading configuration with roller supports and proper instrumentation. The specimens were tested under monotonic static loading in a displacement control mode with $0.01 \mathrm{~mm} / \mathrm{sec}$ loading rate. Meanwhile, strain development, cracking sequence and deflection of beams were monitored during testing. Deflection of the beams were measured using linear voltage displacement transducers (LVDTs) at three different points along the span (i.e. under the loading point and in the middle of both shear spans). Electrical resistance strain gauges were attached to longitudinal reinforcement and CFRP strips to measure the strain development. Fig. 3 shows the test setup, point of measuring the deflection and strain gauges locations. As shown in the Fig. 3, total of 4 
external FRP strain gauges (FS1-FS4) were attached vertically to EB-CFRP strips, and one embedded flexural strain gauge (FLS5) was bonded horizontally to the surface of the middle longitudinal reinforcement bar.

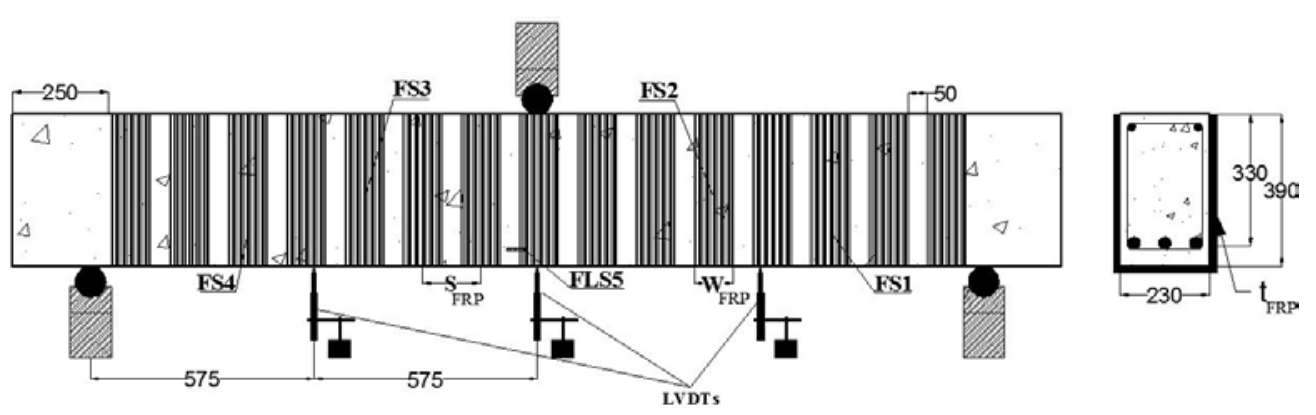

Fig. 3. Test setup and layout of the beam with EB-CFRP and instrumentations (all units are mm).

\section{Experimental results and discussions}

\subsection{Failure modes}

Fig. 4 shows photos of typical tested repaired specimens after failure. As can be seen in Fig.4, all specimens exhibited either full debonding or local debonding of CFRP sheets accompanied by separation of the concrete cover from the beams lateral faces. The beams without minimum stirrups failed in shear by delamination of EB-FRP followed by collapse. However, beams with minimum ratio of steel stirrups experienced a flexural failure followed by local debonding of EB-FRP. The delamination of CFRP strips in beams without stirrups, was quite sudden while in beams with minimum ratio of stirrups it was happening gradually and slower.

Specimen RB-MS-2L-a exhibited yielding of its longitudinal reinforcement recorded by embedded strain gauge attached to it, indicating flexural failure. As for the Specimen RBMS-2L-b, the flexural failure was indicated by exhibiting longitudinal splitting cracks parallel to the compression zone steel reinforcement. It is worth noting that some of the repaired beams exhibited a change in the location of major shear crack after repairing. In other words, the major shear crack was switched from one shear span to the other shear span after repair of the pre-damaged beams. Furthermore, it can be seen in the photos that debonding occurred at the shear span that has experienced a wide diagonal shear crack. Whereas, the other shear span remained intact.

\subsection{Load-deflection curves}

The load-deflection curves of the reference beams and repaired beams are plotted in Fig. 5. As can be inferred from Fig. 5, repair and strengthening of damaged beams increased the initial stiffness of the beams and reduced the relative deformation at peak load compared to the reference beams which is in agreement with the findings in the literature [27]. The exception was the RB-MS-2L-a that exhibited reduction in stiffness when retested the reason for which was the level of damage existed in this particular beam (a chunk of concrete was missing at the bottom of existing shear crack before repair). The loaddeflection diagrams also show that the repaired beams without steel stirrups exhibited very brittle failure by a sudden drop in load resisting. Which is also evident in striking the LVDTs after sudden release of energy as can be inferred from Figure 5a. Whereas, the 
repaired and strengthened beams that were also reinforced with steel stirrups exhibited relatively ductile behaviour shown in Figure $5 \mathrm{~b}$ compared to the beams without stirrups.

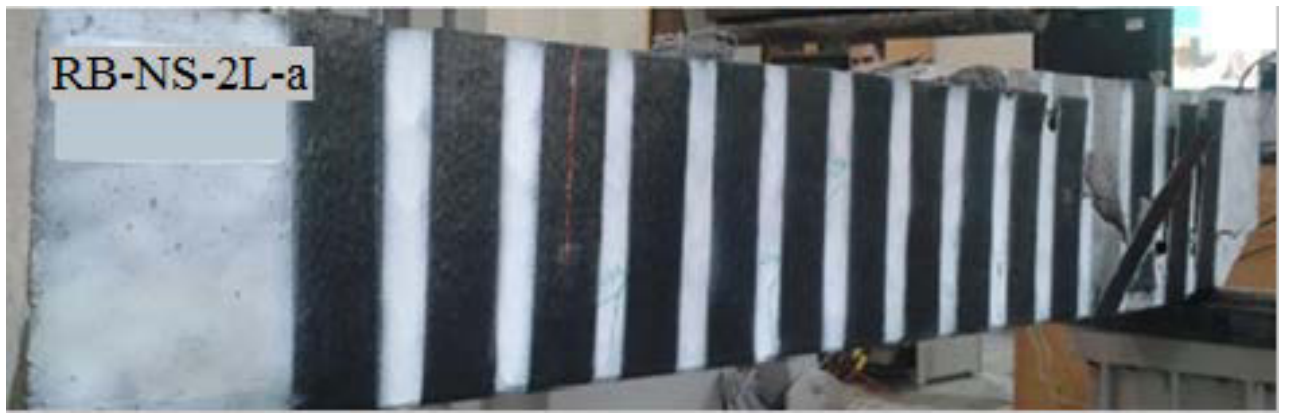

(a)

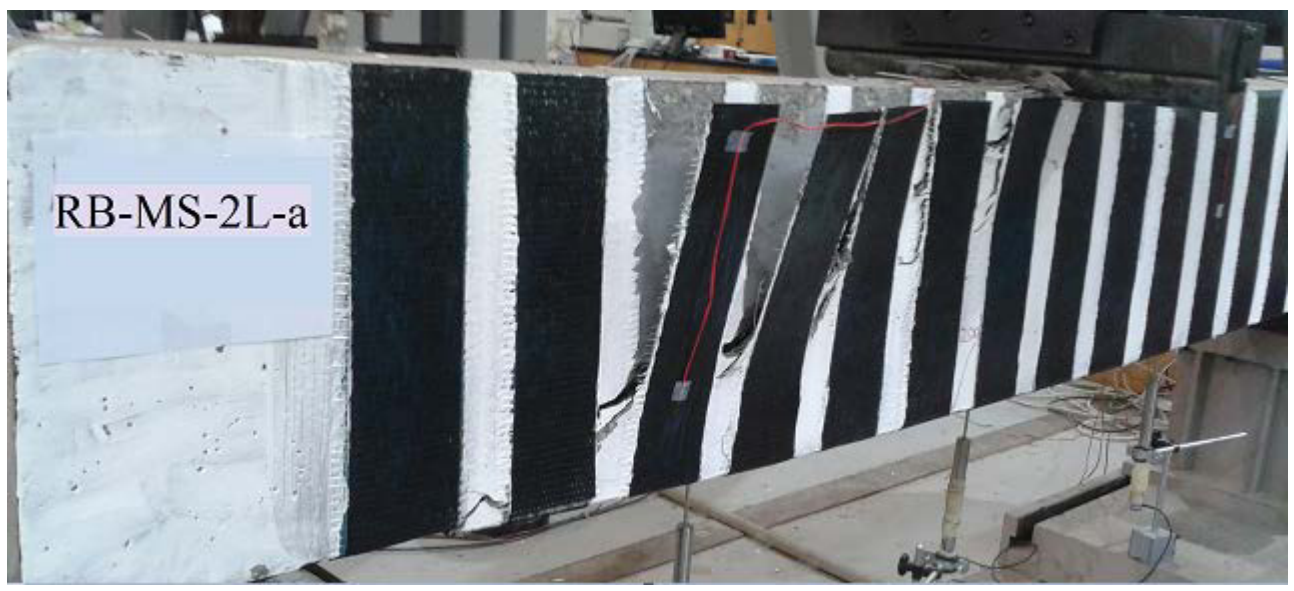

(b)

Fig. 4. Repaired beams after failure (a) without Stirrups, (b) with minimum ratio of stirrups.

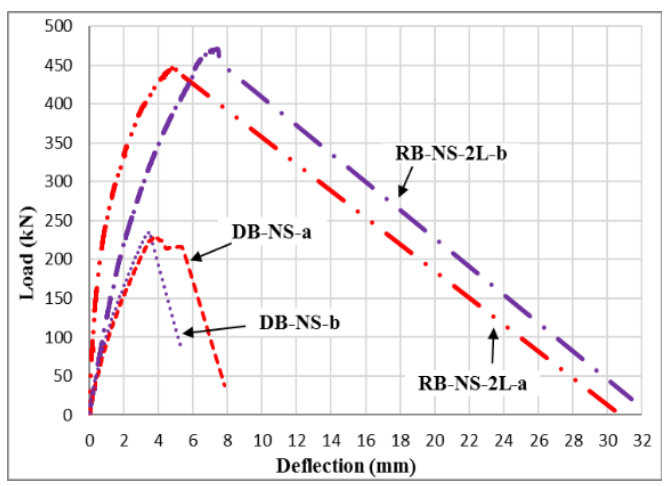

(a)

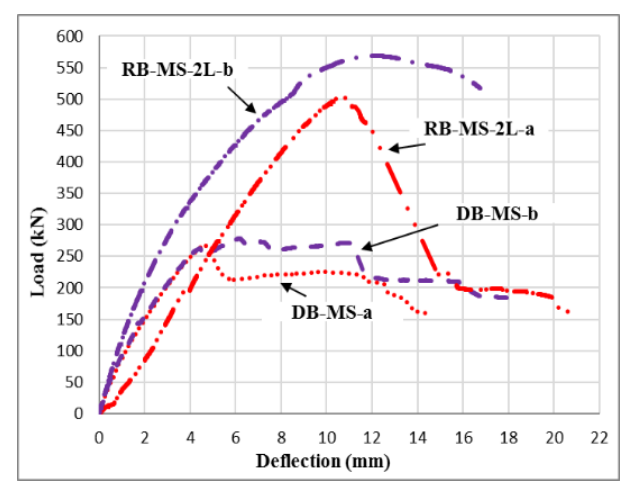

(b)

Fig. 5. Load Vs. Deflection of tested beams, a) Reference and repaired beams without steel stirrups, b) Reference and repaired beams with minimum ratio of steel stirrups. 


\subsection{Strain response}

The maximum measured strain responses in CFRP strips are plotted against the average shear stress $(\mathrm{Vu} / \mathrm{bd}, \mathrm{Vu}=\mathrm{P} / 2)$ of the repaired beams in Fig. 6. The maximum measured CFRP strains plotted in Fig. 6, are not necessarily the absolute maximum CFRP strain as the strain in CFRP is affected by location of strain gauge relative to the location of crack. The EB-CFRP strips (in specimens namely RB-NS-2L-a, RB-NS-2L-b, and RB-MS-2L-a) did not experience significant strain until flexural shear crack initiated at around $2 \mathrm{MPa}$ shear stress. The crack initiation is inferred by the change in the pattern of stress-strain curve as can be noticed in Fig. 6. Which indicates that the crack started to incline and propagate upward but intercepted by the EB-CFRP strips that started engaging in carrying the load. This process continued until the major shear crack was created and opened significantly resulting in debonding of the EB-CFRP and followed by collapse of the beam. However, the exception was the gauge response in specimen RB-MS-2L-b which shows that FRP started engaging in load resisting at around 2.5 MPa shear stress. This particular beam exhibited local FRP debonding and ended to highest contribution by EB-CFRP compared to the other beams. Moreover, it can be inferred from the curves in the Figure that the debonding was sudden in specimens without steel stirrups (sudden drop) while it was gradual in the specimens with minimum ratio of steel stirrups (dropping and resisting).

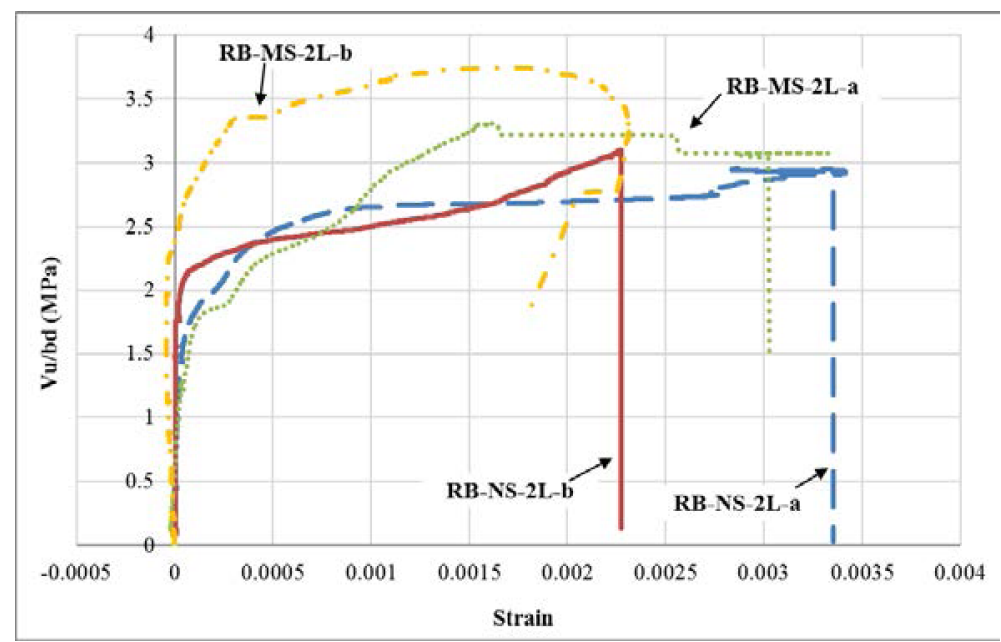

Fig. 6. Average shear stress Vs. maximum CFRP strain responses of repaired beams.

\subsection{Shear Capacity}

The original shear failure load (unstrengthen), as well as the failure load after repair (strengthened), the gain in shear capacity added to the corresponding unstrengthen beam capacity, and the failure mode of the tested beams are summarized in Table 2. It is worth mentioning that one of the damaged beams (namely DB-NS-OL-c) was repaired with epoxy injection only (i.e. RB-NS-0L-c). The reason for testing this particular specimen was to investigate the effect of injected epoxy on shear strength recovery of the repaired beams. From the comparison of test results, it was revealed that the original capacity of the damaged beams was reinstated by epoxy injection only. Indicating that the additional gain in shear capacity of the repaired beams with respect to their original shear strength, is the net contribution of EB-CFRP as tabulated in Table 2. 
The contribution of EB-CFRP to the shear strength (VF), is calculated based on subtraction of the shear load resisted by concrete $(\mathrm{Vc})$, and stirrups (Vs) from the total resisted load after repair as follows:

$$
V_{f}=V_{u}-\left(V_{C}+V_{S}\right)
$$

From the results presented in Table 2, it can be found that repair and strengthening of damaged beams using 2 layers of CFRP, resulted in $95 \%$ increase of the shear strength. It is worth noting here that the additional shear strength provided by EB-CFRP allowed two of the beams (namely RB-MS-2L-a and RB-MS-2L-b) to develop its full flexural capacity. The flexural failure was revealed either from yielding of flexural rebar (i.e. strain response) or the development of the longitudinal splitting cracks at the top surface of the beams parallel to the steel reinforcement.

Table 2. Test results.

\begin{tabular}{|c|c|c|c|c|}
\hline \multirow[b]{2}{*}{ Beam Type } & \multicolumn{2}{|c|}{ Ultimate Shear Capacity } & \multirow[b]{2}{*}{$\begin{array}{c}\text { Strength Gain } \\
\text { Using FRP } \\
\text { V F, exp }, \operatorname{kN})\end{array}$} & \multirow[b]{2}{*}{ FailureMode } \\
\hline & $\begin{array}{c}\text { Original Strength } \\
\text { Vu,exp } \\
(\mathrm{Vc}+\mathrm{Vs}) \\
(\mathrm{kN})\end{array}$ & $\begin{array}{c}\text { After Repair } \\
\text { Vu,exp } \\
\left(\mathrm{Vc}+\mathrm{Vs}+\mathrm{V}_{\mathrm{f}}\right) \\
(\mathrm{kN})\end{array}$ & & \\
\hline RB-NS-2L-a & 115 & 224.5 & 109.5 & Shear + Debonding \\
\hline RB-NS-2L-b & 118 & 235.5 & 117.5 & Shear + Debonding \\
\hline RB-MS-2L-a & 138.5 & 251.5 & 113 & Flexural + Debonding \\
\hline RB-MS-2L-b & 139 & 284 & 145 & Flexural \\
\hline RB-NS-0L-c & 100 & 102 & NA & Shear \\
\hline
\end{tabular}

\section{Conclusions}

The aim of this study was to investigate the performance of EB-CFRP repair technique in shear strength recovery of shear deficient beams. Two types of repaired specimens were tested: beams without stirrups and beams with minimum steel stirrups. 4 beams were repaired and strengthened using EB-CFRP and epoxy injection while one beam was repaired with epoxy injection only. From the experimental results and analysis, it was revealed that repair of severely shear-damaged RC beams using simultaneous application of EB-CFRP and epoxy injection, not only reinstated but also significantly enhanced the original shear capacity of the beams. Based on the results and discussions the following conclusions are drawn;

- The main type of failure was debonding of EB-CFRP where the shear stresses were high and the major shear crack developed, that triggered the delamination of strips and ended by collapse.

- The additional shear strength provided by EB-CFRP system to the shear-deficient beams with minimum ratio of shear reinforcement, resulted in change of mode of failure from pure debonding to flexure failure followed by debonding.

- The use of 2 layers of EB-CFRP discrete strips with $100 \mathrm{~mm}$ width and $150 \mathrm{~mm}$ spacing resulted in approximately $95 \%$ increase in shear strength compared to the original capacity of the reference beams.

In summary, the aforementioned consequences indicate that this technology is an effective approach to improve the shear capacity of shear critical beams. This outcome suggests that EB-CFRP repair technique is a viable alternative for repair and strengthening of existing concrete structures in need of repair. 


\section{References}

1. D. Baggio, K. Soudki, and M. Noël, "Strengthening of shear critical RC beams with various FRP systems," Constr. Build. Mater., vol. 66, pp. 634-644, (2014).

2. G. C. Manosr, K. Katakalos, M. Theofanous, E. Kozikopoulos, and S. Upgrade, "Experimental And Numerical Investigation Of Rectangular R / C Beams Retrofitted Against Shear Utilizing Frp Strips,” no. pp. 12-14,June,(2013).

3. C. Pellegrino and M. Vasic, "Assessment of design procedures for the use of externally bonded FRP composites in shear strengthening of reinforced concrete beams," Compos. Part B Eng., vol. 45, no. 1, pp. 727-741, Feb. (2013).

4. A. A. Shash, "Repair of concrete beams - a case study," vol. 19, pp. 75-79, (2005).

5. T. C. Triantafillou, "Shear Strengthening of Reinforced Concrete Beams Using EpoxyBonded FRP Composites," no. 95, pp. 107-115, (1999).

6. O. Benjeddou, M. Ben Ouezdou, and A. Bedday, "Damaged RC beams repaired by bonding of CFRP laminates," vol. 21, pp. 1301-1310, (2007).

7. J. F. Chen and J. G. Teng, "Shear capacity of FRP-strengthened RC beams: FRP debonding," Constr. Build. Mater., vol. 17, no. 1, pp. 27-41, (2003).

8. A. Bousselham and O. Chaallal, "Shear Strengthening Reinforced Concrete Beams with Fiber-Reinforced Polymer: Assessment of Influencing Parameters and Required Research," no. 101, pp. 219-227, (2005).

9. C. Deniaud and J. J. R. Cheng, "Shear Behavior of Reinforced Concrete T-Beams with Externally Bonded Fiber-Reinforced Polymer Sheets," no. 98, (2001).

10. H. Nikopour and M. Nehdi, "Shear repair of RC beams using epoxy injection and hybrid external FRP," pp. 1865-1877, (2011).

11. M. R. Islam, "Shear strengthening of RC deep beams using externally bonded FRP systems," vol. 27, pp. 413-420, (2005).

12. I. a. Bukhari, R. L. Vollum, S. Ahmad, and J. Sagaseta, "Shear strengthening of reinforced concrete beams with CFRP," Mag. Concr. Res., vol. 62, no. 1, pp. 65-77, Jan. (2010).

13. A. Mofidi and O. Chaallal, "Tests and Design Provisions for Reinforced-Concrete Beams Strengthened in Shear Using FRP Sheets and Strips," Int. J. Concr. Struct. Mater., vol. 8, no. 2, pp. 117-128, (2014).

14. O. Chaallal, "Reinforced-concrete beams retrofi tted in shear," vol. 15, no. 4, (2014).

15. S. Dirar, J. M. Lees, and C. T. Morley, "Precracked reinforced concrete t-beams repaired in shear with prestressed carbon fiber-reinforced polymer straps," ACI Struct. $J$. , vol. 110, no. 5, pp. 855-865, (2013).

16. X. Z. Lu, J. F. Chen, L. P. Ye, J. G. Teng, and J. M. Rotter, "RC beams shearstrengthened with FRP: Stress distributions in the FRP reinforcement," Constr. Build. Mater., vol. 23, no. 4, pp. 1544-1554, Apr. (2009).

17. A. Mofidi, O. Chaallal, and M. Asce, "Shear Strengthening of RC Beams with Externally Bonded FRP Composites : Effect of Strip-Width-to-Strip-Spacing Ratio," no. pp. 732-743, October,(2011).

18. C. Pellegrino and C. Modena, "Fiber-reinforced polymer shear strengthening of reinforced concrete beams: Experimental study and analytical modeling," ACI Struct. J., vol. 103, no. 5, pp. 720-728, (2006).

19. N. Banthia, L. Bisby, R. Britton, R. Cheng, G. Fallis, R. Hutchinson, A. Mufti, K. W. Neale, J. Newhook, K. Soudki, and L. Wegner, “An Introduction to FRP Strengthening of Concrete Structures Composites for Construction," (2004).

20. A. C. I. Committee, Guide for the Design and Construction of Externally Bonded FRP Systems, (2008).

21. Fib bulliton 14 and T. Group 9.3, Externally bonded FRP reinforcement for RC 
structures, (2001).

22. A. Bousselham and O. Chaallal, "Behavior of Reinforced Concrete T-Beams Strengthened in Shear with Carbon Fiber-Reinforced Polymer - An Experimental Study," no. 103, pp. 339-347, (2006).

23. C. Pellegrino and C. Modena, "Fiber Reinforced Polymer Shear Strengthening of Reinforced Concrete Beams with Transverse Steel Reinforcement," J. Compos. Constr., vol. 6, no. 2, pp. 104-111, May (2002).

24. A. Mofidi and O. Chaallal, "Shear Strengthening of RC Beams with EB FRP: Influencing Factors and Conceptual Debonding Model," J. Compos. Constr., vol. 15, no. 1, pp. 62-74, (2011).

25. J. Sim, G. Kim, C. Park, and M. Ju, "Shear Strengthening Effects with Varying Types of FRP Materials and Strengthening Methods," pp. 1665-1680.

26. Yazdanbakhsh A, "Shear Behavior of Synthetic Fiber Reinforced Concrete Beams," MSc Thesis, Univrsity of Sharjah, UAE,(2008)

27. M. Ekenel and J. J. Myers, "Durability performance of RC beams strengthened with epoxy injection and CFRP fabrics," Constr. Build. Mater., vol. 21, no. 6, pp. 11821190, (2007). 